\title{
Dimensões da qualidade de vida no trabalho: representações de equipes de enfermagem em ambiente hospitalar
}

\section{Dimensions of quality of life at work: representations of nursing teams in a hospital environment}

\section{Dimensiones de la calidad de vida en el trabajo: representaciones de los equipos de enfermería en el entorno hospitalario}

Recebido: $12 / 05 / 2020$

Aprovado: 08/10/2020

Publicado: 05/11/2020

\author{
Viviane Aparecida Viana ${ }^{1}$ \\ Rosimár Alves Querino² \\ Ailton de Souza Aragão ${ }^{3}$
}

Esta é uma pesquisa qualitativa realizada em um hospital público federal do interior de Minas Gerais em 2017, com o objetivo de analisar as representações de equipes de enfermagem de um hospital federal de ensino acerca das dimensões constituintes da qualidade de vida no trabalho. Utilizou-se questionário sociodemográfico e entrevista com teste de evocação semiestruturado. Na exploração e análise de dados foram empregadas a estatística descritiva e análise de conteúdo. Pesquisou-se 45 trabalhadores de enfermagem, na sua maioria mulheres - enfermeiros $(17,8 \%)$, técnicos de enfermagem $(57,8 \%)$ e auxiliares de enfermagem $(24,4 \%)$. Os participantes explicitaram conhecer ações voltadas à qualidade de vida no trabalho e destacaram a busca individual e em contextos externos para cuidar de sua saúde. 0 paradoxo que se coloca aos trabalhadores em geral, e às equipes de Enfermagem hospitalar em particular, reside na representação de que o trabalho pode produzir adoecimento e sofrimento, o que se constitui em importante espaço para a atuação da saúde do trabalhador.

Descritores: Qualidade de vida; Saúde do trabalhador; Satisfação no emprego; Equipe de enfermagem.

This is a qualitative research carried out in a federal public hospital in the interior of the state of Minas Gerais, Brazil, in 2017. The study aimed to analyze the representations of nursing teams in a federal teaching hospital about the constituent dimensions of quality of life at work. A sociodemographic questionnaire and interview with semi-structured evocation test were used. In data exploration and analysis, descriptive statistics and content analysis were used. 45 nursing workers were surveyed, most of which were women - nurses (17.8\%), nursing technicians $(57.8 \%)$ and nursing assistants (24.4\%). Participants made it clear they knew actions aimed at quality of life at work and highlighted individual search and in external contexts to take care of their health. The paradox that arises for workers in general, and hospital nursing teams in particular, lies in the representation that work can produce illness and suffering, an important space for the performance of workers' health.

Descriptors: Quality of life; Occupational health; Job satisfaction. Nursing, Team.

Esta es una encuesta cualitativa realizada en un hospital público federal del interior de Minas Gerais, Brasil, en 2017, con el objetivo de analizar las representaciones de los equipos de enfermería de un hospital universitario federal de las dimensiones constitutivas de la calidad de vida en el trabajo. Se utilizó un cuestionario sociodemográfico y una entrevista con una prueba de evocación semiestructurada. Se utilizaron estadísticas descriptivas y análisis de contenido en la exploración y el análisis de los datos. Se investigó a 45 trabajadores de enfermería, en su mayoría mujeres - enfermeros $(17,8 \%)$, técnicos de enfermería $(57,8 \%)$ y auxiliares de enfermería $(24,4 \%)$. Los participantes dijeron conocer las acciones centradas en la calidad de vida en el trabajo y destacaron la búsqueda individual y en contextos externos para cuidar de su salud. La paradoja para los trabajadores en general, y para los equipos de Enfermería hospitalaria en particular, radica en la representación de que el trabajo puede producir enfermedad y sufrimiento, un espacio importante para la acción de la salud del trabajador. Descriptores: Calidad de vida; Salud laboral. Satisfacción en el trabajo; Grupo de enfermería.

1. Enfermeira. Especialista em Enfermagem em Urgência e Emergência. Mestre em Saúde Ambiental e Saúde do Trabalhador, Uberlândia, MG, Brasil. ORCID: 0000-0001-9569-7602 E-mail: vivaviana@yahoo.com.br

2. Cientista Social. Mestre e Doutora em Sociologia. Professora Associada do Departamento de Saúde Coletiva da Universidade Federal do Triângulo Mineiro (UFTM), Uberaba, MG, Brasil. Docente do Programa de Mestrado Profissional em Saúde do Trabalhador e Saúde Ambiental (PPGAT) do Instituto de Geografia (IG) da Universidade Federal de Uberlândia (UFU). ORCID: 0000-0002-7863-1211 E-mail: rosimar.querino@uftm.edu.br

3. Cientista Social. Mestre em Sociologia. Doutor em Enfermagem em Saúde Pública. Pós Doutor em Ciências. Professor Adjunto do Departamento de Saúde Coletiva da UFTM, Uberaba, MG, Brasil. Docente do PPGAT do IG da UFU, MG. 0RCID: 0000-0002-0793-2594 E-mail: ailton.aragao@uftm.edu.br 


\section{INTRODUÇÃO}

A Qualidade de Vida (QV) está intrinsecamente relacionada ao bem-estar e à satisfação de cada pessoa e revela como, em cada contexto sociocultural, os membros da sociedade avaliam o padrão de bem-estar e conforto que possuem ${ }^{1,2}$.

Desde a década de 1990, tem se intensificado a produção acadêmica sobre qualidade de vida motivada, sobretudo, pelos trabalhos da World Health Organization Quality of Life Assessment (WHOQOL) ${ }^{2}$. A consolidação de estudos sobre QV contribuiu para a retomada de pesquisas sobre Qualidade de Vida no Trabalho (QVT), originadas na Inglaterra na década de 1950, quando foram realizados estudos sobre as relações existentes entre indivíduo-trabalhoorganização, resultando na chamada abordagem sociotécnica da organização do trabalho ${ }^{3}$.

Desde então, as abordagens sobre QVT têm ocorrido com contribuições de diversas ciências e sob forte influência do contexto social e econômico no qual se desenvolveram. Houve o incremento da produção acadêmica e, também, sua sedimentação na gestão ${ }^{4}$.

Embora a QVT seja um conceito polissêmico, o que parece transversalizar as abordagens é o reconhecimento da importância da perspectiva dos trabalhadores na compreensão do trabalho nas organizações e dos impactos da QVT no trabalho e nas organizações ${ }^{4-6}$. A QVT se relaciona com questões concernentes às novas tecnologias e formas de organização e o diálogo com noções de saúde e segurança no trabalho, satisfação e motivação ${ }^{7}$, dentre outras.

A abordagem da QVT tem ocorrido em pesquisas envolvendo diferentes categorias profissionais $4,5,8$. Esta abordagem explora as potencialidades junto aos profissionais de enfermagem devido à sua magnitude como força de trabalho nos serviços de saúde ${ }^{9,10}$ e pelos impactos da QVT na saúde e trabalho desses trabalhadores ${ }^{11} \mathrm{e}$, consequentemente, no serviço prestado aos usuários.

O Instituto Brasileiro de Geografia e Estatística ${ }^{9}$ (IBGE) estimou, em 2015, que a área da saúde seria composta por 3,5 milhões de trabalhadores, incluindo os profissionais na ativa e os aposentados, dos quais aproximadamente 50\% atuavam na enfermagem. Destes, $80 \%$ eram técnicos e auxiliares de enfermagem e $20 \%$ eram enfermeiros.

Em trabalho de revisão ${ }^{12}$ sobre produção da enfermagem brasileira, indicou-se a utilização de sete diferentes instrumentos nas pesquisas, dentre os quais destacou-se o Índice de Satisfação Profissional. Embora não houvesse consenso sobre a conceituação de QVT, a satisfação profissional era destacada nas abordagens ${ }^{12}$.

Visando contribuir para a sedimentação de estudos com enfermeiros hospitalares, desenvolveu-se o Instrumento para Avaliação de Qualidade de Vida no Trabalho de Enfermeiros em Hospitais (IQVTE), reduzido a quatro domínios: Identidade e imagem profissional; Condições de trabalho, segurança e remuneração; Valorização e reconhecimento institucional e Integração com a equipe ${ }^{11}$. Assim, é importante garantir que sejam abordados aspectos subjetivos e objetivos presentes no contexto de prática e na percepção dos trabalhadores, o que contribui na apreensão das especificidades da QVT da profissão ${ }^{11}$.

À luz das contribuições da produção acadêmica, para explorar as representações de profissionais de equipes de enfermagem que atuam em ambiente hospitalar, este estudo considera a QVT como um conjunto de dimensões: sociais, cognitivas, emocionais, estruturais, econômicas e condições de salubridade.

A opção por não adotar um instrumento avaliativo da QVT relaciona-se ao interesse pela aproximação com as representações sociais dos trabalhadores de equipes de enfermagem nos seus próprios termos, com perspectiva crítica da qualidade de vida no trabalho e com a sedimentação de estudos no campo saúde do trabalhador.

Assim, este estudo tem como objetivo analisar as representações de equipes de enfermagem de um hospital federal de ensino acerca das dimensões constituintes da qualidade de vida no trabalho. 


\section{MÉTODO}

Trata-se de uma pesquisa descritiva desenvolvida com método qualitativo ${ }^{13}$. 0 cenário de estudo foi um hospital federal de ensino de grande porte do estado de Minas Gerais, referência de região ampliada de saúde cujo atendimento é feito pelo Sistema Único de Saúde (SUS).

Participaram do estudo enfermeiros, técnicos e auxiliares de enfermagem, conforme o Código Brasileiro de Ocupações (CBO), que prestavam cuidados diretos aos usuários e estavam lotados no setor de enfermaria de Clínica Médica do referido hospital.

Os participantes foram recrutados ao longo de suas respectivas escalas de trabalho (manhã, tarde e noite), obtidas no setor da gerência do hospital. Os critérios de inclusão foram: ser profissional da equipe de enfermagem do setor de enfermaria de Clínica Médica; independentemente de idade, sexo, escolaridade e turno de trabalho. Os critérios de exclusão consistiram em: estar em férias ou afastamento por motivos de saúde.

Visando à caracterização socioeconômica dos participantes do estudo foi elaborado questionário com perguntas relativas à idade, sexo, autodeclaração da cor, estado civil, escolaridade, número de filhos, renda familiar, tempo de atuação na área da saúde, vínculos empregatícios, carga horária semanal e turno de trabalho. A equipe realizou dupla digitação de dados em software Microsoft Office Excel ${ }^{\circledR}$.

As dimensões constitutivas da QVT foram assim delineadas: sociais (relações de trabalho, qualidade dos serviços prestados, impactos do trabalho na vida comunitária); cognitivas (conhecimentos pessoais e tecnológicos); emocionais (satisfação, realização pessoal, crescimento profissional); estruturais (condições laborais que promovam o desenvolvimento dos aspectos cognitivos e emocionais); econômicas (melhores rendimentos, consumo de itens de conforto) e condições de salubridade (saúde física e mental dos profissionais).

Para a construção de dados sobre as dimensões constitutivas da QVT, a equipe elaborou um Teste de Evocação Semiestruturado (TESE) conforme proposta de Brabo e Gomes ${ }^{8}$. 0 TESE é considerado como técnica "de identificação e caracterização de representações sociais" cujas perguntas são elaboradas para captar evocações de "componentes da estrutura de possíveis representações sociais", quais sejam ${ }^{8}$ :

3. Conceitual (tem a ver com; é; são): palavras que, teoricamente, possam explicitar os conceitos e/ou estereótipos diretamente associados ao termo indutor;

ii. Atitudinal (é importante para): palavras que, teoricamente, explicitem valores (positivos ou negativos) que o termo indutor desperta no indivíduo;

iii. Prescritivo (precisa/m de): palavras que, teoricamente, explicitem as lacunas/falhas percebidas pelos indivíduos em relação ao termo indutor.

Seguindo esta proposta, o TESE empregado na pesquisa foi composto por três questões norteadoras: $O$ que QVT é? (conceitual); O que fazer para se obter QVT? (atitudinal) e $O$ que pode ser feito para obtenção de QVT? (prescritivo). A aplicação do questionário e a entrevista norteada pelo TESE duraram, em média, 25 minutos. 0 processo analítico dos dados obtidos com o TESE é exemplificado no Quadro 1.

Para garantir sigilo e privacidade quanto aos participantes, foram atribuídos números por ordem de coleta de dados. Nas evocações, são empregadas abreviações (Enf. Para enfermeiros; Tec. Enf. Para os técnicos de enfermagem e Aux. Enf. Para auxiliares de enfermagem), seguidas pelo número atribuído ao participante. 
Quadro 1. Exemplos no processo analítico dos dados obtidos com entrevistas para detalhamento das dimensões da QVT. Hospital federal de ensino do interior de Minas Gerais, 2017.

\begin{tabular}{|c|c|c|c|c|c|}
\hline Part. & Profissão & Sexo & Resposta à questão & Códigos & $\begin{array}{c}\text { Dimensões da } \\
\text { QVT }\end{array}$ \\
\hline 17 & Tec. Enf. & $\mathrm{F}$ & $\begin{array}{l}\mathbf{1} \text { - Conceito de QVT } \\
\text { A qualidade de vida no trabalho a } \\
\text { primeira coisa a pessoa tem que estar } \\
\text { bem de saúde. Bem mesmo. Se tiver } \\
\text { problema de saúde não tem rendimento. } \\
\text { Ter boa comunicação com os colegas, ter } \\
\text { bom relacionamento, ter material bom } \\
\text { para trabalhar, isso é muito importante. }\end{array}$ & $\begin{array}{l}\text { Infraestrutura; } \\
\text { Trabalho em } \\
\text { equipe; } \\
\text { Recursos } \\
\text { materiais; } \\
\text { Segurança. }\end{array}$ & $\begin{array}{l}\text { Social; } \\
\text { Emocional; } \\
\text { Condições de } \\
\text { salubridade. }\end{array}$ \\
\hline 10 & Tec. Enf. & $\mathrm{F}$ & $\begin{array}{l}2 \text { - Atitudinal para QVT } \\
\text { É, a pessoa tem que ter um bom } \\
\underline{\text { equilíbrio no dia a dia, alimentar bem, }} \\
\underline{\text { dormir ter um bom relacionamento. }}\end{array}$ & $\begin{array}{l}\text { Equilíbrio; } \\
\text { Alimentação; } \\
\text { Descanso; } \\
\text { Relacionamentos } \\
\text { bons. }\end{array}$ & $\begin{array}{l}\text { Social; } \\
\text { Emocional; } \\
\text { Estrutural; } \\
\text { Econômico. }\end{array}$ \\
\hline 11 & Aux. Enf. & $\mathrm{F}$ & $\begin{array}{l}3 \text { - Prescritivo para QVT } \\
\text { Mais trocas de ideias no próprio setor } \\
\text { de trabalho. Sabe, é inovar as coisas. } \\
\text { Hoje eu penso que falta atualização de } \\
\text { técnicas, de procedimentos, de } \\
\underline{\text { comunicação de avaliação do paciente e }} \\
\text { de informação. }\end{array}$ & $\begin{array}{l}\text { Comunicabilidade; } \\
\text { Criar; } \\
\text { Atualizar - } \\
\text { técnicas; } \\
\text { Capacidade de } \\
\text { avaliar. }\end{array}$ & $\begin{array}{l}\text { Social; } \\
\text { Cognitivo; } \\
\text { Estrutural; } \\
\text { Econômico. }\end{array}$ \\
\hline
\end{tabular}

Este artigo explora como as dimensões da QVT (sociais; cognitivas; emocionais; estruturais; econômicas e condições de salubridade) são relacionadas pelos participantes aos componentes conceitual, atitudinal e prescritivo obtidos com o TESE. A exploração e a análise de dados ocorreram com a estatística descritiva e a análise de conteúdo ${ }^{14}$.

Para a visualização dos resultados quantitativos do estudo, empregou-se o gráfico tipo Radar, também conhecido como "spidergram", de estrela ou diagrama de Kiviat ${ }^{15}$. Essa estratégia gráfica demonstra sua potencialidade em permitir visualizar a distribuição dos dados entre si, observar o desenvolvimento das dimensões em função de uma resolução de um problema; comparar as diferentes categorias entre si e observar seu alcance, sem 1022ierarquiza-las ${ }^{16}$, pois todas compõem o cenário constitutivo da QVT para os participantes.

No intento de aplicar essa estratégia para o contexto desse estudo e pautando-se numa revisão que analisa as características da QVT e saúde de profissionais de enfermagem ${ }^{12}$, foram delineadas as seguintes dimensões: social, cognitiva, emocional, estrutural, econômica e condições de salubridade.

A dimensão social apresenta a importância das interações entre os participantes, seja no contexto profissional quanto no familiar. Essa dimensão teve como temas aglutinadores: trabalho em equipe, reuniões, vida em família, atividades extra hospitalares, confraternização, interação interpessoal e união da equipe.

A dimensão cognitiva busca evidenciar o lugar de importância da formação continuada para as equipes de Enfermagem e explora temas como formação, atualização, treinamento, cursos, capacitação, acesso à pós-graduação e aprimoramento.

A dimensão emocional está referida à autopercepção das equipes diante de situações que promovem toda sorte de sentimentos que influem na QVT, tais como: satisfação, bem-estar, valorização da profissão (incentivos), acolhimento, acompanhamento terapêutico, estresse e promoção da autoestima.

A dimensão estrutural enfoca aqueles aspectos que influem diretamente na QVT, cuja causa, geralmente, está fora do alcance dos profissionais, embora afetem no desempenho de suas atividades no ambiente de trabalho. Nesta dimensão, estão contidos: assistência ao 
trabalhador, escassez de insumos, subdimensionamento das equipes, remuneração equivalente e redução da carga de trabalho.

A dimensão econômica está referida à possibilidade de consumo imediato de itens de conforto individual e/ou familiar, remuneração/valorização salarial. E as condições de salubridade estão referidas ao ambiente de trabalho, cujos riscos (químicos, físicos, biológicos, ambientais) estão postos nas situações que afetam os trabalhadores no seu processo saúdedoença, individual ou coletivamente. 0 acesso a materiais diversos para execução das atividades, sem improviso, disposição de recursos, manutenção de equipamentos, segurança e ergonomia compõem esta dimensão. Na Figura 1, os eixos partem do centro em direção à margem do gráfico, e estas são as dimensões constitutivas da QVT.

Figura 1. Dimensões constitutivas da Qualidade de Vida no Trabalho. Hospital de Ensino do interior de Minas Gerais, 2017.

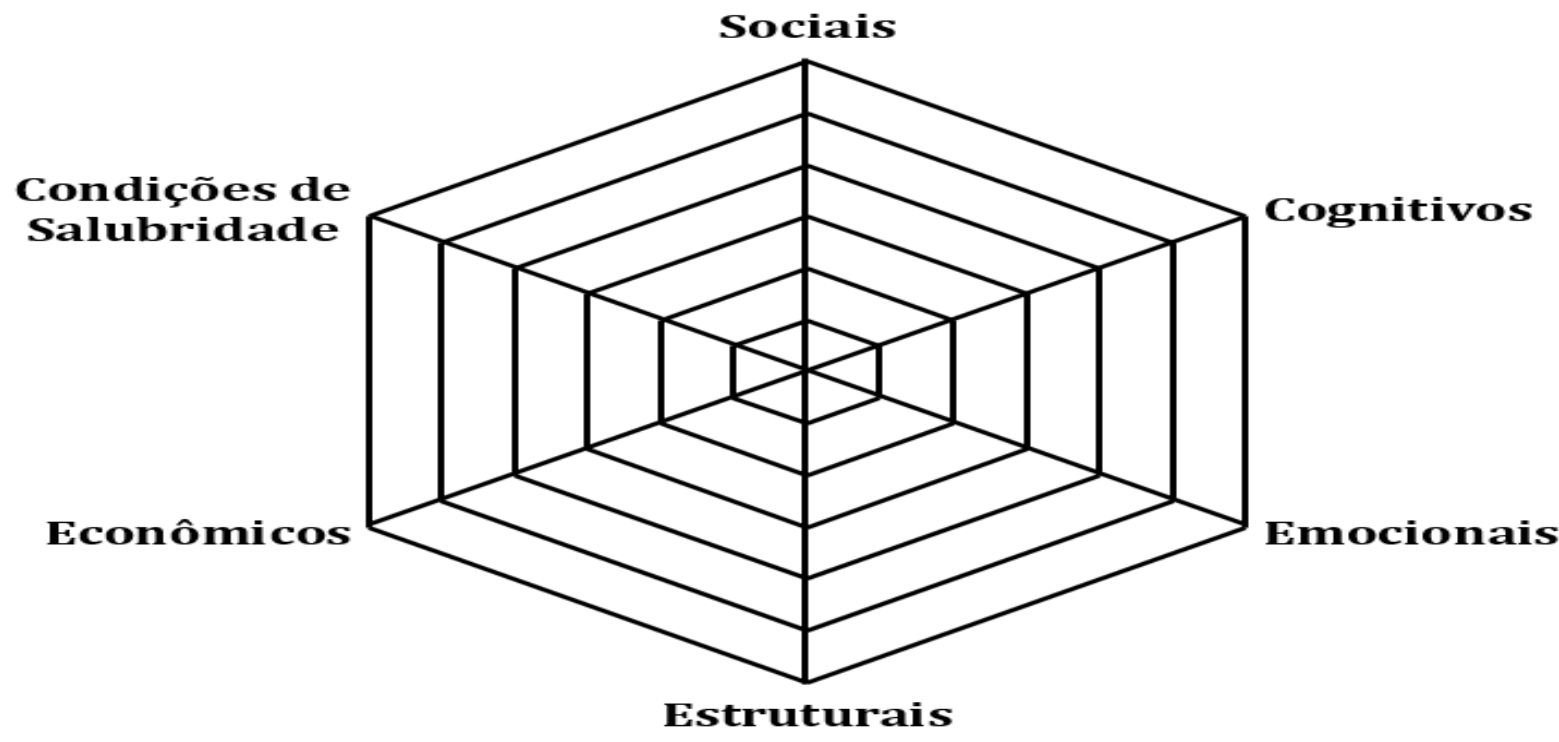

As linhas que formarão um polígono serão determinadas pela quantidade de citações dos participantes à referida pergunta/categoria, compondo uma linha; e as mesmas linhas se conectam uma à outra ${ }^{16}$. A avaliação da QVT é observada pela aproximação das extremidades do polígono formado no Radar. Assim, quanto maior a área da figura construída em direção às extremidades, melhor é o desempenho do hospital referente à característica em análise.

Ao mesmo tempo, um polígono assimétrico revela que o hhospital, na apreensão dos participantes, tem obtido melhor desempenho numa das características da QVT, pois uma de suas extremidades estão mais próximas da borda do Radar do que outra.

Com base no processo analítico, foram construídos três gráficos de rede, um para cada questão do TESE. Aqui, a análise reflete as potencialidades, as fragilidades e as prioridades das dimensões dispostas nos gráficos para os participantes da pesquisa e permite avaliar, por exemplo, qual aspecto merece maior atenção quando da condução de processos participativos na tomada de decisão ${ }^{15}$. A pesquisa foi aprovada por Comitê de Ética em Pesquisa sob CAAE 67537917.5.0000.5154.

\section{RESULTADOS}

Eram elegíveis para participação no estudo 60 profissionais. Após contato e convite individuais, 45 profissionais aderiram à pesquisa, dos quais: enfermeiros $(17,8 \%)$, técnicos de enfermagem $(57,8 \%)$ e auxiliares de enfermagem $(24,4 \%)$. A Tabela 1 apresenta a caracterização sociodemográfica e profissional dos integrantes das equipes de enfermagem do setor de Clínica Médica que participaram do estudo. 
Dentre os participantes do estudo, observou-se maioria do sexo feminino $(86,7 \%)$, autodeclaradas brancas (51,1\%), casadas (55,6\%), com filhos $(71,1 \%)$, com curso de especialização (44,4\%), atuação na área de saúde de 11 anos e mais (48,9\%), com apenas um vínculo de trabalho estatutário $(84,4 \%)$ e com carga horária semanal de trabalho de 40 horas; rendimento familiar entre 4 a 6 salários mínimos (57,8\%). Em relação à idade, predominaram trabalhadores na faixa etária de 41 a 60 anos (42,4\%), variando entre 25 a 63 anos (Tabela 1).

Tabela 1. Caracterização sociodemográfica de equipes de enfermagem de hospital federal de ensino do interior de Minas Gerais, 2017.

\begin{tabular}{|c|c|c|}
\hline Variáveis & $\mathbf{N}$ & $\%$ \\
\hline \multicolumn{3}{|l|}{ Sexo } \\
\hline Feminino & 39 & $86,7 \%$ \\
\hline Masculino & 06 & $13,3 \%$ \\
\hline \multicolumn{3}{|l|}{ Auto declaração de cor } \\
\hline Branca & 23 & $51,1 \%$ \\
\hline Preta & 10 & $22,2 \%$ \\
\hline Parda & 10 & $22,2 \%$ \\
\hline Amarela & 02 & $4,4 \%$ \\
\hline \multicolumn{3}{|l|}{ Idade } \\
\hline Até 30 anos & 05 & $11,1 \%$ \\
\hline De 31 a 40 anos & 18 & $40,0 \%$ \\
\hline De 41 a 60 anos & 19 & $42,2 \%$ \\
\hline 61 anos e mais & 03 & $6,7 \%$ \\
\hline \multicolumn{3}{|l|}{ Estado civil } \\
\hline Casado/união estável & 25 & $55,6 \%$ \\
\hline Solteiro & 12 & $26,7 \%$ \\
\hline Separado/divorciado & 06 & $13,3 \%$ \\
\hline Viúvo & 02 & $4,4 \%$ \\
\hline \multicolumn{3}{|l|}{ Escolaridade } \\
\hline Ensino médio & 03 & $6,7 \%$ \\
\hline Ensino médio/técnico & 12 & $26,7 \%$ \\
\hline Superior & 06 & $13,3 \%$ \\
\hline Especialização & 20 & $44,4 \%$ \\
\hline Mestrado & 04 & $8,9 \%$ \\
\hline \multicolumn{3}{|c|}{ Renda familiar em salários mínimos } \\
\hline Até 3 & 07 & $15,6 \%$ \\
\hline De 4 a 6 & 26 & $57,8 \%$ \\
\hline De 7 a 8 & 08 & $17,8 \%$ \\
\hline \multirow{2}{*}{\multicolumn{3}{|c|}{ Tempo de atuação na área da saúde }} \\
\hline & & \\
\hline Até 3 anos & 03 & $6,7 \%$ \\
\hline De 4 a 6 anos & 15 & $33,3 \%$ \\
\hline De 7 a 10 anos & 05 & $11,1 \%$ \\
\hline 11 anos e mais & 22 & $48,9 \%$ \\
\hline \multicolumn{3}{|l|}{ Vínculos empregatícios } \\
\hline $\mathrm{Um}$ & 38 & $84,4 \%$ \\
\hline Dois & 06 & $13,4 \%$ \\
\hline Três & 01 & $2,2 \%$ \\
\hline \multicolumn{3}{|l|}{ Turno de trabalho } \\
\hline Matutino & 19 & $42,2 \%$ \\
\hline Vespertino & 12 & $26,7 \%$ \\
\hline Noturno & 14 & $31,1 \%$ \\
\hline
\end{tabular}


Com a utilização dos gráficos de rede, foram distribuídos os 459 códigos referentes aos elementos que compõem as noções constituintes da QVT identificadas na análise do TESE, conforme descrito no Gráfico 1. Em todas as questões, o elemento mais citado foi o estrutural, seguido do emocional; este sendo o segundo mais citado apenas na $1^{\text {a }}$ Questão, que evoca o Conceito de QVT, conforme o Gráfico 1.

O Gráfico 1, referente ao componente conceitual de QVT e sua relação com as dimensões que a compõem segundo as evocações dos participantes, demonstrou a relevância da dimensão estrutural (33,1\%) relacionada a trabalhar com prazer, infraestrutura de trabalho, administração, assistência. Foi seguida da dimensão emocional (27\%) que envolve interação interpessoal e satisfação; da social (24,2\%), referente à interação interpessoal e ambiente comunitário; das condições de salubridade (9\%), envolvendo saúde do trabalhador, ambiente favorável, tempo para descanso; da cognitiva $(3,4 \%)$, como conhecer a integralidade, formação, atualização, capacitação; e, por último, da econômica $(3,4)$, que obteve somente seis enunciações (salário, investimento, remuneração).

Gráfico 1. Dimensões envolvidas no conceito de Qualidade de Vida no Trabalho segundo os participantes do estudo. Município do interior de Minas Gerais, 2017.

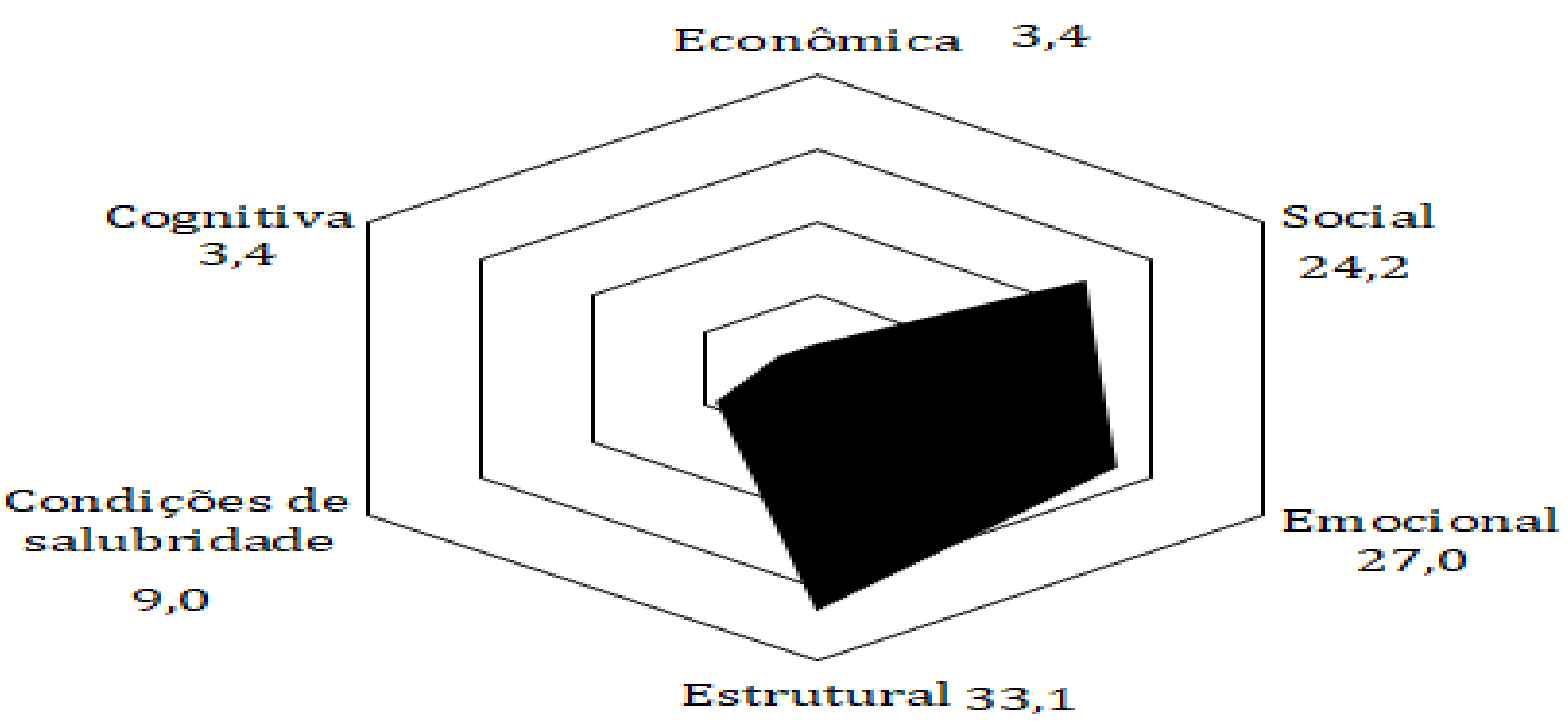

trechos:

O modo como os participantes conceituaram QVT pode ser apreendido nos seguintes

Qualidade de vida no trabalho é um bem-estar físico, emocional, espiritual, social entre as pessoas, entre os grupos de trabalho e na família. (Enf. 4)

Qualidade de vida no trabalho é ter um salário digno, trabalhar em uma carga horária acessível. (Tec. Enf. 16)

Bom, acho que qualidade de vida no trabalho é ter escalas justas, quantidade de folgas suficientes para poder descansar também, respeito acho que é isso. (Aux. Enf. 9)

É trabalhar sem stress, com tranquilidade, com capacitação e com segurança. (Aux. Enf. 11)

[...] é trabalhar em um local que te propicie as mínimas condições para você desempenhar bem seu trabalho, saber que está fazendo aquilo com segurança, com qualidade. (Enf. 5)

Qualidade de vida no trabalho é [...] ter uma boa qualificação, uma boa remuneração para aquele trabalho, ter garantias de propostas de trabalho que sejam sustentáveis, que não sejam volúveis, que não mudem o tempo todo [...] (Enf. 8)

0 Gráfico 2 demonstrou a relevância do aspecto estrutural, com 62 enunciações e evocações referentes ao choque de gestão, plano de metas e redução da carga de trabalho. A dimensão social teve 42 menções, dentre as quais: trabalho em equipe, harmonia na equipe e participar nas reuniões. A dimensão emocional foi enunciada 14 vezes, com aspectos como: prazer no trabalho, valorização, suporte, hospitalidade, respeito dos colegas e dos clientes; as condições de salubridade foram mencionadas 8 vezes, como: segurança no trabalho, escalas 
justas, recursos materiais, capacitação. A dimensão cognitiva teve 7 enunciações, cuja mais citada foi a capacitação e, a econômica teve apenas uma citação.

Gráfico 2. Dimensões envolvidas nas Atitudes para obter QVT, segundo os participantes do estudo. Município do interior de Minas Gerais, 2017.

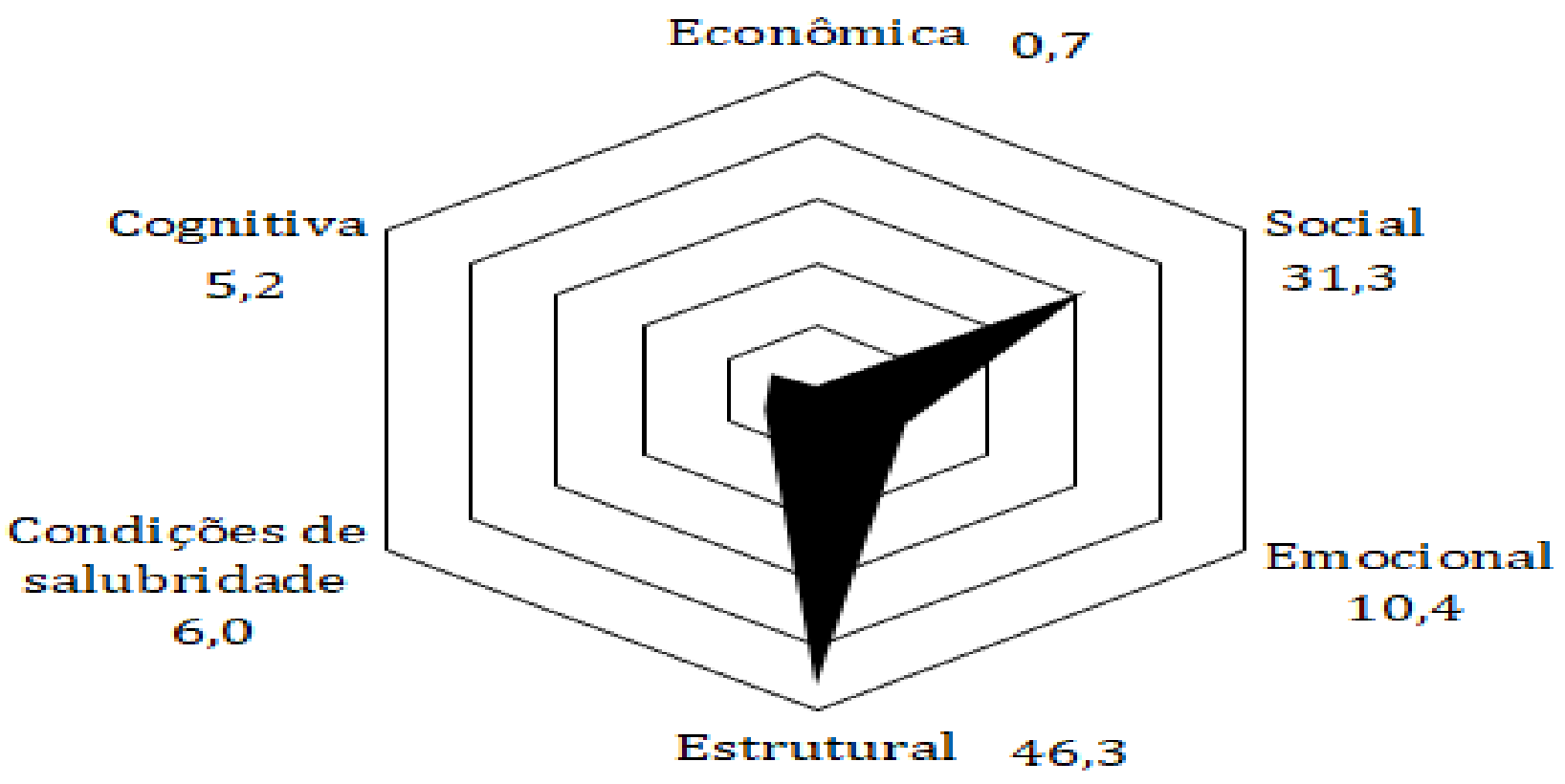

As formas como os integrantes das equipes de Enfermagem apresentaram suas representações sobre a questão atitudinal pode ser apreendida nos seguintes trechos:

[...] precisa melhorar alguns pontos na instituição, né? Aumentar o número de funcionários para ter mais tempo para fazer essas capacitações, mais tempo para fazer as atividades com tranquilidade. Eu penso assim. (Enf. 1)

É necessário que a gente esteja satisfeita, desempenhando seu trabalho da melhor forma, mas para isso tem que estar satisfeita no setor onde você está trabalhando. (Tec. Enf. 21)

Eu creio que hoje [...] o que falta é financeiro da parte do governo para poder estar, é, equipando melhor o hospital e não deixar faltar material. [...] (Aux. Enf. 7)

A codificação das respostas à questão prescritiva do TESE é sistematizada no Gráfico 3. Como visto no Gráfico 3, a dimensão estrutural predominou, com 54 evocações; seguida pela social, com 48; a emocional, com 16; a cognitiva, com 15; a salubridade, com 12 e a econômica, com 1 evocação.

No tocante às seis dimensões da QVT adotadas nesse estudo, observa-se que a estrutural foi a mais citada $(38,1 \%)$ no total das três questões do TESE. A dimensão social correspondeu a 29,0\% das evocações. Sua relevância foi expressa nas três questões do TESE, sendo mais expressiva na Questão Prescritiva para QVT (32,7\%). Tal dimensão expõe as relações de trabalho entre os profissionais, dos profissionais com as chefias, bem como da qualidade do serviço prestado e dos impactos do trabalho na vida comunitária.

A dimensão emocional foi a terceira mais citada no TESE $(17,0 \%)$. Nessa dimensão figuram a segurança, a valorização, a satisfação e o respeito. Tal dimensão foi considerada relevante apenas na Questão Conceitual de QVT (27\%), na qual apareceu como a segunda mais referida.

A dimensão condição de salubridade representou 7,8\% das evocações, sendo mais expressiva na Questão Conceitual $(27,0 \%)$. Esta dimensão está relacionada às menções direcionadas aos aspectos laborais que, explicitamente, são relacionados ao adoecimento do trabalhador.

Por sua vez, a dimensão cognitiva respondeu por 6,1\% das respostas no TESE. Na questão prescritiva para QVT, aparece com 10,2\%. Refere-se aos conhecimentos pessoais e tecnológicos, bem como ao acesso à formação continuada. A dimensão econômica foi enunciada 
em $2 \%$ das evocações. A questão na qual foi mais enunciada foi a Conceitual de QVT $(3,4 \%)$. Relaciona-se a fatores como os rendimentos financeiros e a dimensão que este ocupa na vida dos profissionais.

Gráfico 3. Estratégias para alcançar QVT segundo os participantes do estudo. Município do interior de Minas Gerais, 2017.

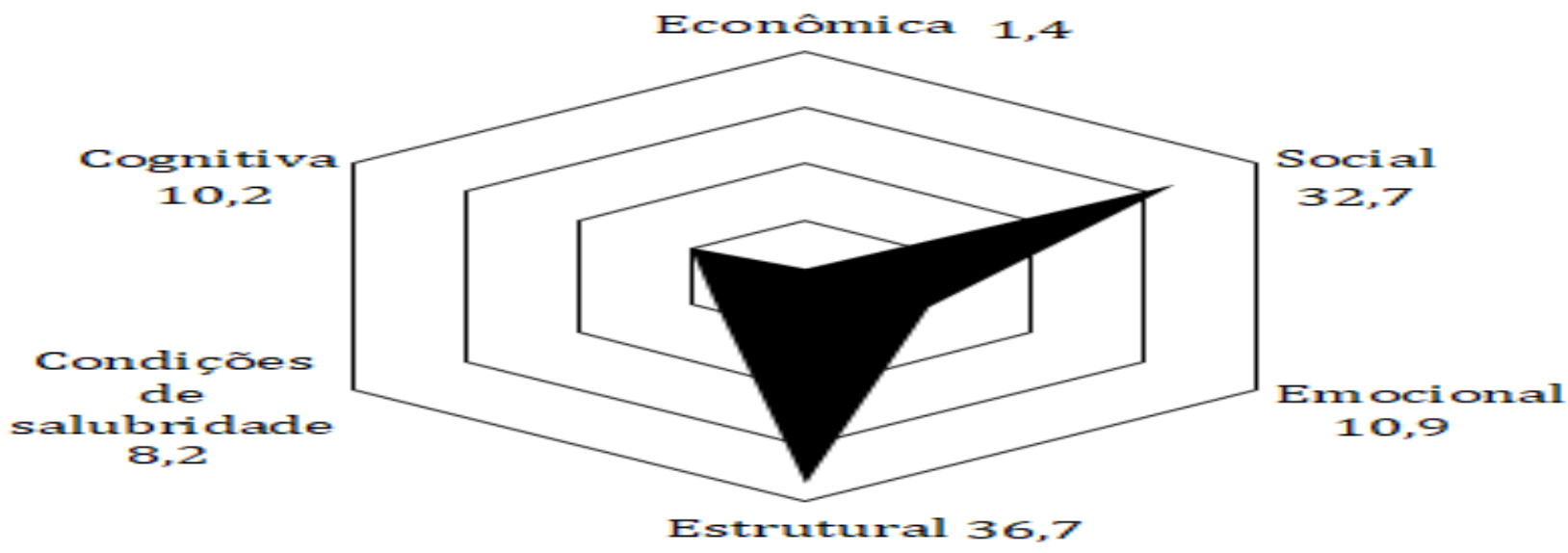

As representações referentes à Questão Prescritiva da QVT foram apreendidas em evocações como as seguintes:

Meu Deus! Assim, no que depende da instituição, a gente não tem muito o que fazer, né? A gestão de estrutura, de material, essa parte é com eles. A gente tem que procurar meios de aprender a lidar com as faltas: falta de material, falta de estrutura, falta de tempo [e] como a gente não dá conta de lidar com essas faltas aqui, [tem que] procurar atendimento fora, uma terapia, fazer atividade física para poder arejar a cabeça. Poder cuidar da nossa saúde porque a gente fica aqui às vezes mal bebe água [...] a gente tem que aprender a lidar com essas faltas e se organizar de uma maneira que a falta que a instituição impõe à gente não nos prejudique fisicamente. (Enf. 5)

Melhorar a comunicação entre os profissionais [...] e a comunicação com o paciente também. [...] Prega tanto a humanização no hospital, mas não tem, não tem a humanização dos profissionais e nem dos pacientes [...] pela superlotação a gente não tem condições de dar humanização [...] Isso afeta não fisicamente, mas emocionalmente [...]. (Enf. 6)

Liberdade de expressão, reuniões, a chefia ouvir os seus funcionários, uma boa política que englobe uma boa harmonia no trabalho [...] que seja bom tanto para instituição quanto para as pessoas que estão trabalhando [...]. (Tec. Enf. 4) o ponto principal seria essa aproximação entre chefia e colaborador para que a gente tivesse uma satisfação a mais, pra gente vir feliz para o trabalho sabendo que a gente vai trabalhar e ter apoio [...] sair com a cabeça legal [...]. (Tec. Enf. 10)

o que tá precisando muito aqui é [...] exercício laboral [...] isso ajuda desestressar o povo que talvez esteja estressado um com o outro, ajuda bastante. (Tec. Enf. 15)

Eu volto a frisar [que] a redução da carga horária seria um up grande para elevar a qualidade de vida do profissional. [...] deveria ter umas dinâmicas voltadas para o profissional, um psicólogo para prepará-lo para as demandas do diaa-dia, para ouvi-lo, acalentá-lo [...] e mais uma coisa: possuir o material necessário, insumos. (Aux. Enf. 5)

\section{DISCUSSÃo}

A predominância de profissionais do sexo feminino $(86,7 \%)$ dentre os participantes do estudo condiz com os resultados de pesquisa empreendida pelo Conselho Federal de Enfermagem (COFEN) ${ }^{17}$, na qual identificou-se que $85,1 \%$ da força de trabalho é feminina.

A presença majoritária de mulheres foi apontada, também, em outro estudo ${ }^{18}$. Este fenômeno não é exclusividade nacional. Uma pesquisa internacional ${ }^{10}$ explorou a realidade de 25 países no período de 2006 a 2014, e apontou relações entre a feminização da força de trabalho em saúde com diferenças salariais, especialmente em países de média e baixa renda. Tais achados ${ }^{10}$ acenam para a importância da abordagem de gênero nos estudos e na discussão de políticas de saúde e gestão de recursos humanos.

As particularidades do estudo aqui empreendido repousam nos vínculos empregatícios e na escolaridade dos participantes, posto sua inserção em instituição federal. Embora tenha predominado um único vínculo pela presença majoritária serem concursados, o estudo acena 
para uma realidade crescente nas instituições federais, que é a existência de outros tipos de vínculos empregatícios que impactam, também, na atuação em outras instituições como reportado por $15,5 \%$ dos participantes. Tal fenômeno é importante na compreensão da elevação da jornada de trabalho semanal e das relações com a baixa remuneração dos trabalhadores ${ }^{19}$ que, por sua vez, pode impactar na QVT.

No que tange às dimensões da QVT analisadas pelo TESE, segundo os participantes, sua conceituação demandaria a consideração da dimensão estrutural que abarca as relações cotidianas com a administração, melhorias na infraestrutura bem como no ambiente de trabalho. Este achado traz a amplitude da representação dos integrantes da equipe de enfermagem sobre a QVT, albergando um olhar sobre as condições estruturais do trabalho e, também, da saúde. Está em sintonia com as reflexões críticas de outro trabalho ${ }^{7}$ que sugere o entendimento da "qualidade (de vida) do trabalho" colocando no centro das reflexões o fato de que a conceituação da QVT exige uma compreensão do trabalho e das possibilidades de controle dos trabalhadores sobre o ambiente, a organização e segurança, entre outros.

0 polígono formado no Gráfico 2, referente à abordagem atitudinal do TESE, revelou aspectos semelhantes à conceituação da QVT por terem predominado as dimensões estrutural e social, o que reforça a importância da organização do trabalho, do ambiente e das relações com/dos/entre profissionais e gestores. A dimensão emocional está presente, haja vista a importância de questões que envolvem sentimentos, conflitos e acontecimentos relacionados à rotina do trabalho ${ }^{20}$. Quanto à dimensão cognitiva, ela foi evocada como necessidade de "aprimoramento" e "planejamento".

A análise dessa questão atitudinal do TESE revelou a necessidade da maior participação dos profissionais nos processos decisórios e gerenciais administrativos que, também, requer processos de capacitação e investimentos na dimensão social.

A prescrição de ações para a QVT, segundo os participantes, demonstra a importância de atuar sobre as estruturas da organização hospitalar, mas de modo planejado, construído com a participação dos trabalhadores e que os mesmos sejam capacitados para avaliar as práticas.

Nessa direção, "participar" e "administrar" incidem sobre o aspecto social e estrutural da QVT, respectivamente. Contudo, trata-se de problematizar o modo como a instituição hospitalar na qual atuam conduz a organização do trabalho e a gestão, posto que, na perspectiva da Saúde do Trabalhador adotada no estudo, a participação dos trabalhadores nas decisões e a possibilidade de sua organização nos locais de trabalho são condições essenciais para a promoção de sua saúde7. De outro modo, o limite das decisões à "administração", aos gestores implicaria no escamoteamento do controle sobre o trabalho ${ }^{7}$.

A concepção hegemônica de QVT possui três características marcantes: foco nos indivíduos, caráter assistencial e ênfase na produtividade. 0 foco nos indivíduos garante a reprodução das condições concretas do trabalho e do ambiente organizacional e espera-se que cada trabalhador possa desenvolver "resistência às adversidades organizacionais"6. 0 caráter assistencial revela-se no fato de que, embora as iniciativas dos programas entendidos como iniciativas de QVT sejam "válidas em si mesmas", não possuem sinergia com as questões postas pelo trabalho e seus contextos assumindo, assim, caráter compensatório e curativo. Por sua vez, a produtividade almejada pelos modelos de gestão visa o produtivismo a despeito do caráter saudável que o trabalho deveria assumir6.

Em pesquisa ${ }^{21}$ com gestores de serviços públicos federais nas esferas do executivo, legislativo e judiciário que desenvolviam Programa de Qualidade de Vida no Trabalho (PQVT), demonstrou-se que projetos de QVT podem padecer de sustentação conceitual, ética e metodológica, especialmente que no tange ao foco no indivíduo como se este fosse capaz de, por si mesmo, angariar todas as condições para experimentar a QVT no ambiente de trabalho, repleto de relações assimétricas, com diversidade de situações.

A proposição de atividades sob o olhar dos participantes do estudo incidiu nas atividades físico-corporais, como a "ginástica laboral", estímulo às "atividades físicas" externamente ao 
ambiente de trabalho; "dinâmicas de grupo" ou ações para "motivação", inclusive obter maior "remuneração" e ações de caráter preventivo aos agravos em saúde como realizar "exames periódicos".

Esse conjunto de recomendações para a QVT não menciona as causas institucionais do estresse, da fadiga, do desgaste físico e mental; tampouco os motivos da sobrecarga que engendram afastamentos do trabalho ${ }^{21,22}$. Fatores estes que podem prejudicar a situação de saúde dos trabalhadores como o agravamento de Doenças Crônicas Não-Transmissíveis (DCNT), como diabetes, hipertensão ou doenças cardiovasculares, e mesmo a obesidade e o uso abusivo de álcool ou tabaco que incidem nas $\operatorname{DCNTs}^{23}$ e, ainda, redundar em motivação para abandono da profissão de Enfermagem ${ }^{19}$.

Em algumas situações, profissionais de enfermagem, cujo trabalho é caracterizado pelo cuidado com vida, negligenciam o seu próprio cuidado e nem sempre se dão conta que o adoecimento profissional pode estar ligado às condições e às cargas de trabalho ${ }^{24}$. Essa realidade exige uma estrutura em que o profissional seja assistido tanto na condição de trabalhador, como na de usuário dos serviços de saúde.

O desempenho das atividades profissionais impacta sobre o processo saúde-doença do trabalhador. Dentre estes impactos estão a sobrecarga física, psíquica e mental que promovem o estresse emocional/ocupacional, resultante de rotinas laborais extenuantes, extensas e desgastantes ${ }^{25}$. Esse cenário de esgotamento das equipes de Enfermagem será responsável pelas insatisfações profissionais, pelos agravos e adoecimentos que afetam, assim, a QVT em todas as suas dimensões em maior ou menor grau.

Dentre as dimensões da QVT, foi investigada a econômica, mencionada poucas vezes pelos participantes: seis vezes na questão conceitual, uma na atitudinal e duas na prescritiva. 0 grupo pesquisado considerou baixa importância dessa dimensão na QVT. Porém, quando são consideradas as enunciações das demais dimensões como, por exemplo, falta de material e de pessoal, falta de manutenção da estrutura física, questões salariais, vê-se a relação desses fatores com o econômico.

De modo geral, as representações dos profissionais de equipes de enfermagem hospitalar sobre a QVT tocam no que pode ser considerado como principal desafio/limite desta abordagem: "aprender a lidar com essas faltas e se organizar de uma maneira que a falta que a instituição impõe à gente não nos prejudique”. As práticas que buscam a QVT [...] objetivam aumentar a resistência dos trabalhadores para continuar habitando um ambiente adverso de trabalho ${ }^{21}$.

Tais condições são agravadas no contexto político contemporâneo, no qual as políticas de cunho neoliberal tem se oposto à reforma sanitária, com impactos significativos no trabalho em instituições públicas e no atendimento à população em geral ${ }^{26,27}$.

\section{CONCLUSÃO}

0 estudo permitiu uma aproximação às representações sociais dos participantes sobre QVT. Ao serem instigados a conceituar QVT, a delinear o que é necessário para atingi-la e, em seguida, sugerir ações para o contexto no qual trabalham, conforme preconiza o método TESE, as narrativas dos integrantes de equipes de enfermagem permitiram um olhar ampliado sobre a representação do trabalho e da saúde do trabalhador em ambiente hospitalar.

0 paradoxo que se coloca aos trabalhadores em geral, e às equipes de Enfermagem hospitalar em particular, reside na representação de que o trabalho pode produzir adoecimento e sofrimento. Assim, a representação da QVT reporta-se de modo profundo à qualidade do trabalho desempenhado. Tal paradoxo ficou explícito na enunciação de ações desenvolvidas, de modo individual, visando manejar as "faltas" que se referem à infraestrutura, às condições e à organização de trabalho.

Os trabalhadores demonstraram reconhecer os limites das ações, geralmente presentes em programas de promoção da QVT e oriundos da administração superior, forçam a busca 
individual pela QV e em contextos externos para cuidar de sua saúde, como ausência de doença. Destarte, a representação da QVT exige acentuar a ampliação dos canais de comunicação, escuta e de maior participação na elaboração de ações relacionadas à totalidade do trabalho.

A exploração das representações de trabalhadores da equipe de enfermagem permitiu uma primeira aproximação ao tema e pode contribuir com a compreensão da instituição hospitalar na qual atuam, mas os resultados não são generalizáveis.

Uma limitação do estudo é não ter particularizado a análise das especificidades das representações de auxiliares, técnicos/as e enfermeiros/as tendo em vista suas diferentes atribuições. Considera-se que técnicas para a construção coletiva de dados, como o grupo focal conjugada ao photovoice, possam expandir o processo de escuta dos trabalhadores e sensibilizá-los para a elaboração de estratégias coletivas voltadas à saúde do trabalhador e promoção da QVT no contexto hospitalar.

\section{REFERÊNCIAS}

1. Minayo MCS, Hartz ZMA, Buss PM. Qualidade de vida e saúde: um debate necessário. Ciênc Saúde Colet. [Internet]. 2000 [citado em 24 mar 2020]; 5(1):7-18. DOI: http://dx.doi.org/10.1590/S1413-81232000000100002

2. World Health Organization. The WHOQOL Group. The World Health Organization quality of live assessment (WHOQOl): development and general psychometric properties. Soc Sci Med. [Internet]. 1998 [citado em 27 abr 2019];12(46):1569-85. $\quad$ DOI: https://doi.org/10.1016/S0277-9536(98)00009-4

3. Dal Forno C, Finger IR. Qualidade de vida no trabalho: conceito, histórico e relevância para a gestão de pessoas. Rev Bras Qual Vida [Internet]. 2015 [citado em 14 mar 2020]; 7(2):103-12. DOI: $10.3895 /$ rbqv.v7n2.3015

4. Farias DLG, Domingues Júnior PL, Castro MCD, Saldanha JAV, Oliveira VM. Satisfaction level of the quality of working life: a research with professors of the administration course of a private higher education institution in Juiz De Fora (Brazil). Braz J Develop. [Internet]. 2020 [citado em 27 abr 2020]; 6(1):638-56. D0I:10.34117/bjdv6n1-045

5. Medeiros JP, Melo AL, Guerra LCB. Avaliação da qualidade de vida no trabalho dos policiais de uma delegacia especializada da cidade do Natal/RN. Rev Bras Estud Seg Pública [Internet]. 2018 [citado em 25 abr 2020]; 11(2):42-58. DOI: https://doi.org/10.29377/rebesp.v11i2.294 6. Ferreira MC. Qualidade de vida no trabalho: uma abordagem centrada no olhar dos trabalhadores [Internet]. Brasília, DF: Edições Ler, Pensar, Agir; 2011 [citado em 25 abr 2020]. 320p. Disponível em: http://ergopublic.com.br/arquivos/1359392512.36-arquivo.pdf

7. Lacaz FAC. Qualidade de vida no trabalho e saúde/doença. Ciênc Saúde Colet. [Internet]; 2000 [citado em 27 abr 2020]; 5(1):151-61. DOI: https://doi.org/10.1590/S141381232000000100013

8. Brabo JC, Gomes ASA. Teste de evocações semiestruturado como ferramenta para o estudo de representações sociais: possibilidades de aplicação na pesquisa em ensino de ciências. In: IX Encontro Nacional de Pesquisa em Educação em Ciências; 2013; Águas de Lindóia. Águas de Lindóia, SP: ABRAPEC; 2013 [citado em 1 mar 2018]. Disponível em: www.nutes.ufrj.br/abrapec/ixenpec/atas/resumos/R0482-1

9. Instituto Brasileiro de Geografia e Estatística. Projeção da população do Brasil e das unidades da federação [Internet]. Rio de Janeiro: IBGE; 2015 [citado em 20 maio 2018]. Disponível em: http://www.ibge.gov.br/apps/populacao/projecao/

10. Shannon G, Minckas N, Tan D, Haghparast-Bidgoli H, Batura N, Mannell J. Feminisation of the health workforce and wage conditions of health professions: an exploratory analysis. Hum Resour Health [Internet]. 2019 [citado em 27 abr 2020]; 17:72. DOI: 10.1186/s12960-0190406-0

11. Kimura M, Carandina DM. Desenvolvimento e validação de uma versão reduzida do instrumento para avaliação da Qualidade de Vida no Trabalho de enfermeiros em hospitais. Rev 
Esc Enferm USP [Internet]. 2009 [citado em 25 abr 2020]; 43(Esp):1044-54. DOI: https://doi.org/10.1590/S0080-62342009000500008

12. Schmidt DRC, Dantas RAS, Marziale MHP. Qualidade de vida no trabalho: avaliação da produção científica na enfermagem brasileira. Acta Paul Enferm. [Internet]. 2008 [citado em 27 abr 2020]; 21(2):330-7. DOI: https://doi.org/10.1590/S0103-21002008000200016

13. Creswell JW. Projeto de pesquisa: métodos qualitativo, quantitativo e misto. 3ed. Porto Alegre: Artmed; 2010. 296p.

14. Minayo MCS. O desafio do conhecimento. 15ed. São Paulo: Hucitec; 2017. 408p.

15. Rocha MB, Moreira DC, Bispo JP. Conselho de saúde e efetividade participativa: estudo sobre avaliação de desempenho. Cad Saúde Pública [Internet]. 2020 [citado em 26 abr 2020]; 36(1):e00241718. DOI: https://doi.org/10.1590/0102-311X00241718

16. Sousa JC, Alves MB, Leocádio L, Rossato R. Gestão ambiental da cadeia de suprimentos LARG: uma proposta de instrumento diagnóstico para avaliação dos fornecedores. Braz Bus Rev. [Internet]. 2019 [citado em 27 abr 2020]; 16(6):537-54. DOI: https://doi.org/10.15728/bbr.2019.16.6.1

17. Machado MH, Aguiar Filho W, Lacerda WF, Oliveira E, Lemos W, Wermelinger M, et al. Características gerais da enfermagem: o perfil sócio demográfico. Enferm Foco [Internet]. 2015 [citado em 27 abr 2020]; 6(1/4):11-7. DOI: https://doi.org/10.21675/2357707X.2016.v7.nESP.686

18. Aquino RL, Aragão AS. Impacto do trabalho noturno na vida do profissional de enfermagem do sexo masculino. Rev Enferm UFPE on line [Internet]. 2017 [citado em 27 abr 2020]. 11(10):3725-31. DOI: 10.5205/reuol.12834-30982-1-SM.1110201704

19. Oliveira DR, Griep RH, Portela LF. Intention to leave profession, psychosocial environment and self-rated health among registered nurses from large hospitals in Brazil: a cross-sectional study. BMC Health Serv Res. [Internet]. 2017 [citado em 27 abr 2020]; 17(1):21. DOI: 10.1186/s12913-016-1949-6

20. Matoso KML, Rodrigues DNJ. Qualidade de vida dos profissionais de enfermagem no ambiente hospitalar. Rev Ciênc Desenvolv. [Internet]. 2016 [citado em 27 abr 2020]; 9(2):2-19. Disponível

http://srv02.fainor.com.br/revista/index.php/memorias/article/view/570/280

em:

21. Ferreira MC, Alves L, Tostes N. Gestão de Qualidade de Vida no Trabalho (QVT) no serviço público federal: o descompasso entre problemas e práticas gerenciais. Psic Teor Pesq. [Internet]. 2009 [citado em 26 abr 2020]; 25(3):319-27. DOI: https://doi.org/10.1590/S010237722009000300005

22. Santos S, Macedo F, Silva L, Resck Z, Nogueira DA, Terra FS. Acidentes de trabalho e autoestima do profissional de enfermagem em ambiente hospitalar. Rev Latinoam Enferm. [Internet]. 2017 [citado em 26 abr 2020]; 25:e2872. DOI: https://doi.org/10.1590/15188345.1632.2872

23. Salvagioni DAJ, Melanda FN, Mesas AE, González AD, Gabani FL, Andrade SM. Physical, psychological and occupational consequences of job burnout: a systematic review of prospective studies. PLoS One [Internet]. 2017. [citado em 23 abr 2020]; 12(10):e0185781. DOI: $10.1371 /$ journal.pone.0185781

24. Salimena AMO, Melo MR, Thorferhn MB. Assistência de enfermagem oncológica: reflexão sobre enfrentamento, riscos ocupacionais e qualidade de vida dos profissionais. Enferm Bras. [Internet]. 2019 [citado em 28 abr 2020]. 18(4):577-81. DOI: https://doi.org/10.33233/eb.v18i4.2479

25. Ribeiro RP, Marziale MHP, Martins JT, Galdino MJQ, Ribeiro PHV. Estresse ocupacional entre trabalhadores de saúde de um hospital universitário. Rev Gaúcha Enferm. [Internet]. 2018 [citado em 28 abr 2020]; 39:e65127. https://doi.org/10.1590/1983-1447.2018.65127.

26. Nunes JA. A contra-reforma sanitária, ou o neoliberalismo como patologia [Internet]. Público, Lisboa, Portugal, 21 set 2018 [citado em 27 abr 2020]. Disponível em: 
publico.pt/2018/09/21/mundo/opiniao/a-contrareforma-sanitaria-ou-o-neoliberalismocomo-patologia-1844664

27. Campos GWS. SUS: o que e como fazer? Ciênc Saúde Colet. [Internet]. 2018 [citado em 28 abr 2020]; 23(6):1707-14. DOI: https://doi.org/10.1590/1413-81232018236.05582018

\section{CONTRIBUIÇÕES}

Viviane Aparecida Viana e Ailton de Souza Aragão contribuíram na concepção, obtenção dos dados e análise, redação e revisão. Rosimár Alves Querino participou da análise de dados, redação e revisão.

\section{Como citar este artigo (Vancouver)}

Viana VA, Querino RA, Aragão AS. Dimensões da qualidade de vida no trabalho: representações de equipes de enfermagem em ambiente hospitalar. REFACS [Internet]. 2020 [citado em inserir dia, mês e ano de acesso]; 8(Supl. 3):1019-1032. Disponível em: inserir link de acesso. DOI: inserir link do DOI.

\section{Como citar este artigo (ABNT)}

VIANA, V. A.; QUERINO, R. A.; ARAGÃO, A. S. Dimensões da qualidade de vida no trabalho: representações de equipes de enfermagem em ambiente hospitalar. REFACS, Uberaba, MG, v. 8, p. 1019-1032, 2020. Supl. 3. Disponível em: inserir link de acesso. Acesso em: inserir dia, mês e ano de acesso. DOI: inserir link do DOI.

\section{Como citar este artigo (APA)}

Viana, V.A., Querino, R.A., \& Aragão, A.S. (2020). Dimensões da qualidade de vida no trabalho: representações de equipes de enfermagem em ambiente hospitalar. REFACS, 8(Supl. 3), 1019-1018. Recuperado em inserir dia, mês e ano de acesso de inserir link de acesso. DOI: inserir link do DOI. 